\title{
O Critério de Conexão da Nacionalidade na Doutrina e na Legislação de Direito Internacional Privado Brasileiro (1863-1973)
}

\author{
Nationality as a Connecting Factor in the Legal Doctrine and Legislation of \\ Brazilian Private International Law (1863-1973)
}

\author{
Aline Beltrame de Moura ${ }^{1}$ \\ ${ }^{1}$ Universidade Federal de Santa Catarina, Florianópolis - SC, Brasil.
}

Resumo: O presente artigo tem como objetivo analisar a utilização do princípio da nacionalidade como critério de conexão para o conflito de leis acerca do estatuto pessoal do indivíduo no ordenamento jurídico brasileiro. O problema proposto consiste em verificar se a teoria do jurista italiano Pasquale Stanislao Mancini teria influenciado a escolha legislativa de favorecer o predomínio do critério de conexão da nacionalidade até o advento da Lei de Introdução ao Código Civil de 1942, a qual passou a privilegiar o critério do domicílio. A hipótese é a de que a legislação e parte da doutrina brasileira receberam influências do pensamento do jurista italiano, mas também da doutrina francesa sobre a matéria. Do ponto de vista metodológico, a pesquisa utiliza como fundamento a História do Pensamento Jurídico de Paolo Grossi.

Palavras-chave: Direito Internacional Privado. Critérios de conexão. Nacionalidade.

\begin{abstract}
The purpose of the present article is to analyze the utilization of the nationality principle as a connecting factor for conflict of laws regarding the personal statute of the individuals in Brazilian legislation. The proposed problem consists on verifying whether the theory of the Italian jurist Pasquale Stanislao Mancini had influenced the legislative choice to favor the prevalence of the criterion of nationality as a connecting factor until the advent of the 1942 Law of Introduction to the Civil Code, which began to favor the domicile criterion. The hypothesis is that the legislation and part of the Brazilian doctrine were influenced by the thinking of the Italian jurist, but also by the French doctrine on the matter. From a methodological point of view, the research uses as foundation Paolo Grossi's History of Legal Thinking.
\end{abstract}

Keywords: Private International Law. Connecting Factor. Nationality.

Recebido em: $14 / 01 / 2018$

Revisado em: 25/07/2018

Aprovado em: 05/08/2018 


\section{Introdução}

Pasquale Stanislao Mancini (1817-1888) ${ }^{1}$ é um dos três grandes estudiosos do direito internacional privado do século XIX, ao lado de Friedrich Carl von Savigny (1779-1861) e Joseph Story (1779-1845). Juntos eles elaboraram tratados que influenciaram o desenvolvimento da matéria em diversos sistemas jurídicos, tal qual o brasileiro. O presente artigo objetiva examinar, em um primeiro momento, por meio de quais parâmetros foi realizada a recepção de ideias e de noções que permearam o pensamento do jurista italiano Mancini acerca do princípio da nacionalidade nas páginas das doutrinas de direito internacional privado, produzidas por juristas brasileiros ao longo do século XIX até a década de 1970 do século passado. Para tal, dá-se particular relevo ao exame dos manuais como aqueles publicados por Pimenta Bueno, Teixeira de Freitas, Carlos Augusto de Carvalho, João Monteiro, Pedro Lessa, Rodrigo Octávio, Pontes de Miranda, Francisco Campos, Clovis Beviláqua, Lafayette Pereira, Wilson de Souza Campos Batalha, Oscar Tenório, Sérgio Loreto Filho, Amilcar de Castro e Haroldo Valladão.

Também serão contempladas, a tal fim, as polêmicas e críticas doutrinárias tecidas neste âmbito tendo em vista as alterações legislativas ocorridas durante o período de predomínio do princípio da nacionalidade na legislação pátria para depois ser abandonado em favor do elemento de conexão do domicílio como critério definidor da escolha da lei aplicável ao estatuto pessoal do indivíduo nos casos de conflito de leis no espaço.

O lapso temporal proposto considera como marco inicial do presente estudo a obra de José Antonio Pimenta Bueno, intitulada "Direito Internacional Privado e aplicação de seus princípios com referencia às leis particulares do Brazil" de 1863, primeiro estudo sistematizado de direito internacional privado brasileiro, e o termo final os livros sobre a matéria elaborados por Haroldo Valadão e Sérgio Loreto Filho, ambos de 1973,

\footnotetext{
${ }^{1}$ Pasquale Stanislao Mancini (Castelbaronia, 1817 - Nápoles, 1888) foi jurista, professor universitário e político, tendo sido ministro da Instrução Pública (1862), ministro da Justiça (1876) e ministro dos Negócios Estrangeiros (1881) do Reino da Itália. Nesse sentido ver: Storti Storchi (2013, p. 1.244-1.248).
} 
os quais trazem as últimas análises doutrinárias sobre a reforma da Lei de Introdução ao Código Civil de 1942 que levou a substituição do critério de conexão da nacionalidade por aquele do domicílio no que se refere ao estatuto pessoal do indivíduo.

O problema ao qual a presente pesquisa procura responder é se a teoria internacional privatista proposta por Mancini efetivamente influenciou a doutrina brasileira no tocante à escolha legislativa do critério de conexão da nacionalidade para o conflito de leis acerca do estatuto pessoal até o advento da Lei de Introdução ao Código Civil de 1942, a qual passou a privilegiar o critério do domicílio. A hipótese é que a doutrina e a legislação brasileira efetivamente receberam influências do pensamento do jurista italiano, embora tenham igualmente havido muitas críticas doutrinárias que rechaçavam a nacionalidade como elemento de conexão apto a ser aplicado ao ordenamento jurídico pátrio, as quais acabaram por fortalecer a corrente defensora do critério do domicílio como aquele mais apto à realidade brasileira. Do ponto de vista metodológico, a pesquisa utiliza como fundamento a História do Pensamento Jurídico de Paolo Grossi (2007, p. 13-20; 2005, p. 31-45).

\section{O Critério de Conexão da Nacionalidade na Teoria de Direito Internacional Privado de Mancini}

As regras de conexão são normas disciplinadas pelo direito internacional privado que indicam o direito aplicável às diversas situações jurídicas conectadas a mais de um sistema jurídico (DOLINGER. 2011, p. 295). O Direito internacional privado, por sua vez, cuida em primeiro lugar de classificar a relação jurídica dentre um rol de qualificações, isto é, de categorias jurídicas. Em seguida, localiza a sede jurídica dessa relação e, por fim, determina a aplicação do direito vigente nesta sede. Com a expressão "estatuto pessoal" se alude à capacidade e aos direitos de personalidade das pessoas físicas, das relações de família e das sucessões em razão de morte do indivíduo.

A base para a elaboração dos pressupostos teóricos que sustentaram o princípio da nacionalidade no direito internacional privado é encontrada 
nas célebres conferências proferidas por Mancini na Universidade de Turim nos anos de 1851 e 1852, respectivamente, "Del principio della nazionalità come fondamento del diritto delle genti" e "Lineamenti del nuovo e del vecchio diritto delle genti". Aquela foi proferida quando Mancini tomou posse da primeira cátedra universitária italiana dedicada ao direito internacional, na Universidade de Turim, em 22 de janeiro de 1851, sendo posteriormente publicada no volume Diritto Internazionale (1873). A efetiva consolidação das teorias de Mancini no campo do direito internacional privado somente ocorreu com a leitura de um relatório em Genebra, publicado no Jornal de Clunet em 1874, no qual assenta sua doutrina na ideia de extraterritorialidade, denominando-a personalidade do direito (CASTRO, 1956, p. 193).

Mancini elabora sua teoria nacionalista em um contexto bastante peculiar. Em meados do século XIX, a Itália se encontrava dividida em principados que possuíam governo e leis próprias, mas passava por um intenso movimento de luta pela unificação. Sendo Mancini um dos políticos defensores da unidade italiana, propõe que a Nação é a que deveria ocupar o papel de interlocutor no direito internacional, pois esta seria o verdadeiro sujeito do ordenamento internacional, ente real e permanente, criado pela história e não pela política como seria o Estado.

Os elementos do conceito de "Nação" formulado no Risorgimento receberam um primeiro delineamento em um universo eminentemente político, em que correntes de matriz ideológica nacionalista tentavam legitimar a independência de determinados territórios europeus - como a Itália ou a Hungria - submetidos de modo integral ou fragmentário à soberania de Estados terceiros. Tal fenômeno pode ser facilmente observado ao longo da primeira metade do século XIX, sobretudo na cultura jurídico-política italiana e francesa. Entre os italianos, se destacam juristas importantes do período, como Pellegrino Rossi, Gian Domenico Romagnosi, Giuseppe Mazzini, Luigi Taparelli D’Azeglio, Giacomo Durando e Vincenzo Pagano ${ }^{2}$. Envolvida no romantismo que dominava a literatura, a

\footnotetext{
${ }^{2}$ Elementos que vão compor os conceitos de "Nações" e "Nacionalidade" em Mancini podem ser encontrados em ROMAGNOSI, Gian Domenico. La scienza delle costituzioni. Firenze: a spese degli editori, 1850; MAZZINI, Giuseppe. Nazionalità. Qualche idea su una costituzione nazionale. In: Edizione nazionale degli scritti di Giuseppe Mazzini. Vol.
} 
ideia da existência de uma nação italiana ganhava vida própria e contornos antropomórficos, sendo que essa nova "Nação" deveria tomar para si a condição de protagonista do direito no cenário internacional.

Portanto, tomando por base as Nações, ele constrói uma nova ideologia unificante onde a nacionalidade é mais que a mera comunhão de regiões, raças, línguas, costumes, história, leis e religiões, uma vez que estes elementos, derivados de Gianbattista Vico, seriam como matéria inerte, aguardando o suspiro de vida. O espírito vital, o elemento psicológico, viria a ser a consciência de nacionalidade, a subjetividade espiritual de unidade moral (MANCINI. 2000, p. 45) que permite aos indivíduos que moram no mesmo território, com os mesmos costumes e a mesma língua, de reconhecerem-se reciprocamente como concidadãos.

A ideia de cidadania vem, dessa forma, proposta como princípio de nacionalidade. Nesse sentido, o Code Civil francês de 1804, mais conhecido como Código Napoleônico, enunciava em seu art. 7 que "O exercício dos direitos civis é independente da qualidade de cidadão, a qual não se adquire nem se conserva senão em conformidade com a lei constitucional". Mancini (1959, p. 371) reforça que o Código Napoleônico foi o primeiro a colocar o estatuto pessoal do francês na sua lei nacional, o qual estende seu manto protetivo para qualquer país estrangeiro em que um francês se encontre. Observa-se, porém, que o critério de conexão da nacionalidade utilizado pela legislação francesa somente prevê a aplicação da lei francesa quando um nacional francês estiver em um país terceiro, excluindo a aplicação da lei de origem de um estrangeiro que esteja em território francês. Percebe-se, portanto, uma notável diferença na aplicação do princípio da nacionalidade como critério de conexão no código civil de 1804 em comparação com aquele previsto pela Lei brasileira de 1916, pois no sistema francês, somente é beneficiário deste critério o francês no exterior. Por sua vez, no Brasil o princípio da lei nacional era previsto tanto para o caso de brasileiros no exterior quanto de estrangei-

VI. Imola: Galeati, 1908; TAPARELLI D’AZEGLIO, Luigi. Della nazionalità. Genova: Ponthenier, 1847; DURANDO, Giacomo. Della nazionalità italiana. Saggio politicomilitare. Losanna: Bonamici, 1846; PAGANO, Vincenzo. Del diritto della nazionalità italiana. Napoli: Rondinella, 1861. 
ros no Brasil, demonstrando uma aplicação mais ampla do critério por se tratar de uma norma bilateral, diferentemente da francesa.

O conceito de cidadania, sob tal perspectiva, afirmou-se em grande parte dos Estados europeus com a consolidação da tríade cidadão-nação-Estado. E essa é a ideia de fundo que guia, no plano do direito internacional privado, a submissão do indivíduo à própria lei nacional em grande parte das situações jurídicas que lhe digam respeito, em particular ao seu estatuto pessoal (MOSCONI; CAMPIGLIO, 2010, p. 6). Em outras palavras, o ordenamento nacional do indivíduo seria imposto como fruto de todos os fatores naturais que se encontram na base do princípio de nacionalidade, independente de onde ele se encontre e sob qual jurisdição esteja submetido.

Mancini entendia que o direito civil privado é pessoal e nacional e, como tal, protege e acompanha a pessoa também fora da sua pátria. Ao contrário, o direito público é territorial, domina todos os fatos que a ele digam respeito e indistintamente a todos os homens que nele habitam, indígenas ou estrangeiros (MANCINI, 1959, p. 391). Para ele o direito internacional compreenderia tanto o direito público quanto o direito privado, porquanto independência no interior e respeito da coexistência com outras nações eram considerados como princípios basilares da sua teoria (JAYME. 2000, p. 8). A estreita interação entre direito internacional público $^{3}$ e privado encontra respaldo, por exemplo, quando propõe que

${ }^{3}$ Para uma revisão historiográfica mais profunda sobre o impacto da teoria de Pasquale
Stanislao Mancini na ciência do direito internacional público, ver: CATELLANI, Enrico.
La dottrina italiana nel diritto internazionale nel secolo XIX. Roma: Romana Editoriale,
1935, p. 14 ss.; e, após, SERENI, Angelo. The italian Conception of International Law.
New York: Columbia, 1943, DROETTO, Antonio. Pasquale Stanislao Mancini e la
Scuola Italiana di Diritto Internazionale del secolo XIX. Milano: Giuffrè, 1954; e, mais
recentemente, CAZZETTA, Giovanni. 2013; COLAO, Floriana. L' 'idea di nazione" nei
giuristi italiani tra ottocento e novecento. Quaderni fiorentini per la storia del pensiero
giuridico, XXX (2001), p. 255 ss.; e, STORTI, Claudia. Empirismo e scienza: Il crocevia
del diritto internazionale nella prima mettà dell'Ottocento. In: NUZZO, Luigi et VEC,
Miloš (Ed.s). Constructing International Law. The Birth of a Discipline. Frankfurt-am-
Main: Klostermann, 2012, p. 51 ss.; STORTI, Claudia. L'indipendenza dell'Italia nel
diritto internazionale della prima metà dell'Ottocento in Problemi giuridici dell'Unità
italiana. Milano: Giuffrè, 2013, pp. 33 ss.; STORTI, Claudia. Pasquale Stanislao Mancini. 
somente por meio da estipulação de tratados internacionais, que tornem obrigatória a aplicação de algumas regras de direito internacional privado por parte dos Estados, é que seria possível assegurar a tomada de decisões uniformes diante da pluralidade de legislações civis e penais existentes. O pragmatismo de suas ideias encontrou respaldo na Conferência de Haia de direito internacional privado, organização internacional criada em 1893 e que objetiva a uniformização das regras em torno dessa matéria.

O jurista italiano sustenta, ainda, que é a nacionalidade a ligar o indivíduo ao Estado e a distinção entre cidadãos e estrangeiros estabelece o critério para a concessão dos direitos individuais. Sob tal perspectiva, cidadania e nacionalidade tornam-se uma coisa só, e essa fusão faz com que se perca o elemento mais característico da cidadania, isto é, seu viés político, uma vez que os direitos reconhecidos tendo por base a nacionalidade são os civis, enquanto o direito de voto e a efetiva participação política não eram considerados por Mancini elementos essenciais da cidadania pois insuficientes a identificar e distinguir um povo de outro, ${ }^{4}$ um cidadão de um estrangeiro. A cidadania seria o lugar jurídico da construção ideológica baseada na comunhão étnica, ou mesmo racial, e como tal não poderia vir a ser compreendida senão como um instrumento de integração nacional (BONI; FERRERO. 2004, p. 50-51).

Segundo Mancini, portanto, o sistema de direito internacional privado encontrava a sua ratio no princípio de nacionalidade. Era um princípio funcional à aposição de limites à independência territorial. Era necessário distinguir entre as relações públicas e privadas de um indivíduo, isto é, diferenciar o que, no direito medieval, era chamado de "estatuto pessoal" e

In: BIROCHI, Italo, CORTESE, Ennio, MATTONE, Antonello et MILETTI, Marco Nicola (a cura di). Dizionario Biografico dei Giuristi Italiani (XII - XX secolo). Vol. II. Bologna: Il Mulino, 2013, p. 1244 ss.; VIDARI, Gian Savino Pene. La prolusione di Pasquale Stanislao Mancini sul principio di nazionalità (1851). In: CAZZETTA, Giovanni (a cura di). Retoriche dei giuristi e costruzione dell'identità nazionale. Bologna: Il Mulino, 2013, p. 117 ss.; DAL RI Jr., Arno. Pasquale Stanislao Mancini. In: DAL RI Jr., Arno; VELOSO, Paulo Potiara de A.; LIMA, Lucas Carlos (Org.). A formação da ciência do direito internacional. Ijuí: Unijuí, 2014.

${ }^{4}$ Para uma teoria geral sobre cidadania, ver: COSTA, Pietro. Cittadinanza. Roma-Bari: Editori Laterza, 2013. 
“estatuto real". O estatuto pessoal representava os direitos dos indivíduos na sociedade, sendo o elemento subjetivo da nacionalidade, enquanto o estatuto real representava o elemento político, ou seja, os direitos da sociedade para com os indivíduos (STORTI STORCHI. 1990, p. 309-311).

No tocante a sua teoria, Mancini apoia o seu sistema de direito internacional privado em três pilares fundamentais: nacionalidade, liberdade individual e soberania territorial. Segundo sua teoria, o direito privado consistiria, inicialmente, em normas que fossem em qualquer caso aplicadas aos indivíduos onde quer que se encontrassem, possuindo, portanto, efeitos também extraterritoriais (VITTA. 1980, p. 346).

Assim, o direito privado compreenderia, de um lado, o chamado "direito privado necessário" relativo às normas sobre direitos pessoais, de família e sucessórios, o qual não poderia ser modificado nem pela manifestação de vontade do indivíduo, uma vez que é produto dos fatores naturais derivantes da sua nacionalidade, como situação geográfica, clima, tradições históricas e religião. Desse modo, a diferença existente entre os direitos dos mais variados povos ocorre simplesmente por que é o produto das particularidades de tais fatores. Tendo por base este raciocínio, Mancini defende a aplicação da lei nacional como regra de conexão para os casos de conflito de leis no âmbito dos casos que envolvessem o direito privado necessário.

Em sentido oposto, encontra-se a teoria defendida pelo alemão Friedrich Karl von Savigny, segundo a qual para determinar a lei aplicável a um caso com elementos de estraneidade, importa a sede da relação jurídica, isto é, o território jurídico ao qual essa relação pertence segundo a sua própria natureza. Assim, Savigny é claro ao afirmar que

Se se perguntar qual é o direito aplicável aos diferentes estados da pessoa que determinam a capacidade jurídica e a capacidade de agir, responde-se: é pura e simplesmente o direito local, ao qual essa pessoa está sujeita por força de seu domicílio. [...] Penso, portanto, que, quando se trata das qualificações pessoais cada um deve sempre ser julgado de acordo com o Direito de seu domicílio, qualquer que seja o tribunal chamado a se pronunciar e qualquer que 
seja o objeto do litígio, a qualificação pessoal ou seus efeitos jurídicos (SAVIGNY. 2004, p. 128-132)

Perfazendo uma análise crítica de tal teoria e ao mesmo tempo defendendo o ponto de vista do seu conterrâneo, o italiano Dionisio Anzilotti afirma que a doutrina de Savigny não é tanto um sistema de direito internacional privado, mas um método de estudá-lo (ANZILOTTI. 1960, p. 107).

Dando continuidade a teoria internacional privatista de Mancini, existiria também o "direito privado voluntário" relativo à matéria de obrigações contratuais, no qual prevaleceria a autonomia da vontade das partes. Seria representado pela liberdade individual, pela faculdade de o indivíduo derrogar as suas normas de direito nacional para submeter determinada relação jurídica que possua algum elemento de estraneidade a uma lei diversa, de acordo com sua livre preferência.

Por fim, o terceiro elemento da teoria manciniana refere-se à soberania territorial que se traduz no fato de que as exigências do Estado são respaldadas pelas leis de direito público e de ordem pública que, dada a sua natureza territorial, são expressões do princípio de soberania. Nesse caso, tende a prevalecer a territorialidade do Estado e, por isso, a aplicação de determinadas normas estrangeiras pode ser vetada em nome da soberania estatal.

É um recurso frequentemente utilizado nos casos em que os estrangeiros, em condições de paridade com os cidadãos, são sujeitos às normas penais, às normas de ordem pública e de direto público de um Estado (CASTELLANI. 1902, p. 159-160), limitando, de certa forma, os campos de ação dos elementos da nacionalidade e da liberdade individual. Nas palavras de Mancini,

[...] a ordem jurídica é caracterizada pela conciliação da liberdade privada ou individual com o exercício da potestade social, isto é, pelas relações entre a lei do Estado e as prerrogativas do indivíduo, 
entre ordem política e ordem civil das relações domésticas e privadas. (MANCINI. 1959, p. 387)

Em sentido amplo, a ordem pública compreende também, independentemente do país, o respeito aos princípios superiores da moral humana e social, como os bons costumes, os direitos primitivos inerentes à natureza humana e as liberdades que não podem ser derrogados por imposição de qualquer instituição, governo ou atos de vontade. Se as leis positivas de um Estado, uma decisão estrangeira ou mesmo atos ou contratos realizados no estrangeiro violam estes princípios, cada soberania, longe de aceitar estas ofensas à natureza e à moralidade humanas, poderá, a justo título, recusar qualquer efeito e a execução sobre o seu território (OLIVEIRA FILHO. 1945, p. 250-251).

Eis aí a doutrina de Mancini que, por Haroldo Valladão, pode ser assim sintetizada: leis de direito público, territoriais, aplicando-se a todos no respeito à soberania estatal; de direito privado necessário, pessoais, de efeito extraterritorial, acatando a nacionalidade de cada indivíduo; e de direito privado voluntário, dependendo da autonomia da vontade, sob a influencia direta da liberdade, com a ação dos princípios da liberdade, da nacionalidade e da soberania e independência políticas (VALLADÃO. 1973, p. 130).

Ao reconhecer a diversidade de legislações existentes e a natureza cosmopolita do ser humano, Mancini encontra os fundamentos do seu princípio da extraterritorialidade. Daí decorre que todos os países estão comprometidos não por mera cortesia, mas por força do direito internacional a aplicar aos estrangeiros o direito de seu país de origem. Seria, portanto, um dever internacional, manifestação de respeito e de solidariedade humana o respeito a lei nacional do estrangeiro (BASSO. 2013, p. 156). Pontes de Miranda, em curso publicado pela Academia de Direito Internacional de Haia em 1932, ao afirmar que do mesmo modo que o Estado dita as leis de nacionalidade igualmente dita a extensão cronoló-

\footnotetext{
5 “'L'ordine giuridico è costituito dalla conciliazione della libertà privata o individuale con l'esercizio della potestà sociale, cioè, dalle relazioni tra la legge dello Stato e le prerogative dell'individuo, tra l'ordine politico e l'ordine civile dei domestici e privati rapporti." Tradução da autora.
} 
gica e espacial do seu direito, corrobora o caráter obrigatório que "[...] les Etats sont obligés de reconnaître les systèmes et ordres juridiques des autres Etats.” (MIRANDA. 1932, p. 555; MIRANDA, 1935, p. 565-566).

Internacionalmente, o princípio da nacionalidade de Mancini foi consagrado no Instituit de Droit International, nas Sessões de Oxford, 1880, para o estado e a capacidade, de Heidelberg, 1887, e Lausanne, 1889, para o casamento, seus efeitos e o divórcio. Nas Conferências de Haia, de 1893, 1894, 1900 e 1904 foram aprovadas convenções que ainda se encontram vigentes entre alguns Estados da Europa, sobre casamento, divórcio e separação, e tutela de 1902 e sobre efeitos pessoais e patrimoniais do casamento e curatela, de 1905 (VALLADÃO. 1973, p. 133).

\section{O Critério de Conexão da Nacionalidade na Doutrina e na Le- gislação Brasileira}

No Brasil, segundo Valladão, desde 1850 a legislação pátria adotara o princípio da lei nacional, por meio de seus costumes e da aplicação do direito desta (1967, p. 344). De fato, a doutrina de Mancini angariou muitos adeptos no Brasil ${ }^{6}$, principalmente no período em que o ordenamento

\footnotetext{
${ }^{6}$ A teoria de Pasquale Stanislao Mancini foi objeto de análise no Brasil, também no âmbito do direito internacional público, nos escritos de PEREIRA, Lafayette Rodrigues. Princípios de Direito Internacional. Rio de Janeiro: Jacintho Ribeiro dos Santos Editor, 1902, p. 59, nota 1; PEDERNEIRAS, Raul. Direito internacional compendiado. Rio de Janeiro: Freitas Bastos, 1931, p. 70 ss.; AMERICANO, Jorge. O novo fundamento do direito internacional e seu esteio na conciencia universal. São Paulo: Renascença, 1945, p. 21 ss.; FARO JUNIOR, Luiz P. F. Direito Público Internacional. Rio de Janeiro: Haddad, 1956, p. 55 ss.; ACCIOLY, Hildebrando. Tratado de Direito Internacional Público. Vol. I. Rio de Janeiro: s/e, 1956, p. 111 ss.; BOSON, Gerson de Britto Mello. Curso de Direito Internacional Público. Belo Horizonte: Bernardo Alvares editora, 1958, p. 247 ss.; OLIVEIROS LITRENTO. Manual de Direito Internacional Público. Rio de Janeiro: Forense, 1968, p. 57 ss. Menções à teoria de Mancini estão ausentes em outros autores brasileiros de destaque na ciência do direito internacional, como BEVILÁQUA, Clóvis. Direito Público Internacional. Rio de Janeiro: Freitas Bastos, 1939; MELLO, Celso Albuquerque de. Curso de Direito Internacional Público. 1967. Para maiores detalhes, ver a comunicação apresentada por Arno Dal Ri Jr. na European Society for Comparative Legal History - Fourth Biennial Conference: "Comparative Legal History: Culture, Identity and Legal Instrumentalism”, na Universidade de Gdánz, na Polônia, em
} 
jurídico brasileiro filiava-se ao critério de conexão da nacionalidade. Até o advento do Código Civil de 1916, as regras referentes aos conflitos de leis eram disciplinadas no Brasil pelas Ordenações Filipinas e por algumas normativas nacionais. Dentre os quais se destacam o Decreto n. 737, de 1850 , sobre o juízo no processo comercial, o qual determina que o estado e a capacidade dos estrangeiros residentes no Império será regulado pela sua lei nacional; o Regulamento n. 855, de 1851, sobre arrecadação de bens de estrangeiros domiciliados no Brasil, o qual se refere à lei nacional do de cujus, dando-lhe competência para regular a ordem de sucessão e a validade das disposições testamentárias, bem como a Lei n. 1.096 de 1860 sobre concessões de chancelarias estrangeiras, a qual prevê a lei nacional como reguladora do estado e da capacidade do estrangeiro. Em comum, portanto, todos determinavam como regra de conexão o princípio da lei nacional.

No período do Brasil imperial, dois juristas de expressão tratam da matéria internacional privatista: José Antonio Pimenta Bueno e Augusto Teixeira de Freitas. O primeiro escreveu seu tratado em 1863, tendo dado início ao estudo doutrinário sistematizado do direito internacional privado no Brasil. Apesar da imprecisão característica de sua época, dado o atraso em que se encontrava a disciplina, pode-se dizer que Pimenta Bueno contribuiu para o estudo da disciplina da melhor maneira que seria possível naquele tempo (BATALHA. 1961, p. 288). Ele toma por guia principal Jean-Jacques Gaspard Foelix, auxiliado por Massé, Pardessus e Bello, seguindo, portanto, o influxo das ideias francesas, preferindo a lei nacional para base dos direitos da personalidade e da família, não somente por ser uma legislação metódica e clara, mas também por ser seguida por muitas nações (BUENO. 1863, p. 08).

Pimenta Bueno, embora não faça referência expressa à Mancini, é um ferrenho defensor do princípio da nacionalidade contra o da territorialidade tal qual Pontes de Miranda o será em seus trabalhos publicados na década de 30. Para ambos os juristas, o princípio da nacionalidade é mais seguro, uma vez que o domicílio voluntário poderia ser alterado com

julho de 2016, intitulada "Mancini in the Platine Basin: The reception of the Principle of Nationalities in Argentina and Brazil" 
facilidade, tornando-se, portanto, inconveniente e, inclusive, tendo a desvantagem de ser uma potencial "porte ouverte de la fraude" (MIRANDA. 1932, p. 555; MIRANDA, 1935, p. 557), pois ao trocar o domicílio automaticamente seriam alteradas também as regras aplicáveis ao seu estatuto pessoal. Já a mudança de nacionalidade não é tão fácil e, por essa razão, oferece uma base segura e de consequências lógicas para os direitos pessoais, os quais não devem ser tão variáveis (BUENO. 1863, p. 22). Confirmando a segurança jurídica verificada na aplicação do princípio da lei nacional, Pimenta Bueno afirma que

A nacionalidade a que elle pertence diz: 'Este homem é meu súbdito, e seus direitos e obrigações pessoaes estão qualificados e definidos, elle pode percorrer diferentes paizes, e só eu, isto é, só minha lei pode servir de unidade, de regra permanente e immutavel para as relações que elle possa ter'; segundo esta julguem todos de suas condições, habitações ou idoneidades, assim é justo, e não haverá confusão, nem inconvenientes. (BUENO. 1863, p. 28)

Uma leitura atenta da teoria de Pimenta Bueno nos revela que o autor ao tratar do princípio da nacionalidade tinha como preocupação de fundo, em realidade, a manutenção dos direitos adquiridos, problemática que somente mais tarde seria efetivamente desenvolvida por juristas europeus, tal qual Antoine Pillet. O francês foi o que mais deu destaque a teoria dos direitos adquiridos, atribuindo-lhe condição de objeto do direito internacional privado, independente da questão do conflito de leis, porém, antes dele, já se falava no reconhecimento dos direitos adquiridos de acordo com a lei competente, como se observa nos ensinamentos de Schaeffner na Alemanha, Vareilles-Sommieres na França e Dicey na Inglaterra, citados inclusive por Pillet (1903, p. 496).

Um dos argumentos utilizados por Pimenta Bueno e Pontes de Miranda na defesa da utilização da nacionalidade como critério de conexão no direito internacional privado é que o estatuto pessoal do indivíduo deve atender aos interesses, às necessidades, aos costumes, à índole, à religião e às condições especiais de cada povo em específico (BUENO, 1863, p. 28). E somente a aplicação da lei nacional seria capaz de atender a estas diversas facetas de modo efetivo. Pontes de Miranda é enfático ao 
propor que a imposição da lei do domicílio ao estrangeiro que se encontra no território do país de recepção constituiria uma medida política violenta, já que somente a lei nacional seria exata e permitiria assegurar a harmonia entre a função social do indivíduo dentro da sociedade na qual vive e a liberdade do mesmo de se deslocar pelo mundo (MIRANDA. 1932, p. 558 e 562 ).

Revelando o dissídio fundamental entre o critério nacionalista e o domiciliar para fixação da lei pessoal, Pedro Lessa, em 1900, não denegou aplausos ao Código Civil alemão que acabara de entrar em vigor nas terras germânicas e que consagrara o princípio da nacionalidade, o qual, segundo o doutrinador, se conforma com as ideias mais modernas (LESSA. 1900, p. 196).

Na mesma época em que Pimenta Bueno lançava seu manual internacional privatista, Teixeira de Freitas publicava a Consolidação das leis civis (1858) e o Esboço ao Código Civil (1864), primeira tentativa de elaboração de um código civil brasileiro. Embora não tenha sido diretamente utilizado, o projeto inspirou Clóvis Beviláqua na elaboração do codex civilista que entrou em vigor de 1917, bem como teve grande influência no processo de codificação de outros países latino-americanos, como o Código civil argentino de 1869. Na realidade, não se pode deixar de mencionar que Vélez Sarsfield, autor da codificação argentina, teve conhecimento dos trabalhos de Teixeira de Freitas, tendo com ele se correspondido e considerando-o como um luminar do direito (WALD, 2004, p. 257).

Invocando o pensamento de Savigny, Teixeira de Freitas afirma que é o domicílio e não a nacionalidade que determina a sede jurídica das pessoas a fim de definir a lei aplicável a sua capacidade ou incapacidade. Entende o jurista que as nações são entre si independentes e, por isso, têm o poder exclusivo de promulgar suas leis que obrigam todas as pessoas e coisas somente nos limites do seu território. Quaisquer efeitos que as leis estrangeiras possam ter no território de outro Estado, dependem absolutamente do consentimento expresso, ou tácito desse Estado. No mais, todos os escritores reputam a eventual extraterritorialidade das leis como ato de benevolência, um dever de sociabilidade humana, um fato de mútua conveniência e não como uma condição obrigatória (FREITAS. 
1876, p. CXXXII). Além disso, No campo do direito internacional privado dos contratos, Teixeira de Freitas foi um dos primeiros a defender o princípio da autonomia privada das partes na escolha da lei aplicável, embora a legislação brasileira nunca tenha convertido em lei tal orientação (SANTLEBEN. 1985, p. 269).

Aqui se observa o primeiro ponto de ruptura com a doutrina de Mancini, a qual apregoa que os Estados são obrigados pelo direito internacional a aceitar a aplicação de normas jurídicas estrangeiras dentro do seu território em nome do princípio da nacionalidade e que isto não se trata de mera cortesia ou ato de benevolência. Trata-se, nas palavras de Mancini (1959, p. 377), de um "dovere di giustizia internazionale". Caso contrário, toda teoria da extraterritorialidade cairia por terra, uma vez que dependeria da discricionariedade de cada país em aplicar ou não a lei nacional do estrangeiro que esteja sob a sua jurisdição.

Ainda no final do século XIX, críticas à doutrina manciniana ganham força com a publicação de Carlos Augusto de Carvalho em 1899. O autor, em obra sobre a consolidação das leis civis, afirma que o discurso proferido por Mancini em 1851 era "cheio de seduções" e, por isso, acabou angariando muitos adeptos. O princípio da nacionalidade baseia-se, segundo o civilista, na ideia de expansão da soberania pela conquista ou pelas esferas de influência, sendo um discurso simpático porque patriótico e odioso porque ameaçador (CARVALHO, 1899, p. LXXVII). Nota-se aqui o forte sentimento do perigo de um neocolonialismo, mascarado por detrás de uma teoria supostamente jurídica.

Além disso, ressalta que a doutrina de aplicação da lei nacional tal qual defendida por Mancini é, em realidade, jurídica na superfície e política no fundo (CARVALHO, 1899, p. LXXXI). De fato, essa parece ser uma crítica recorrente entre os doutrinadores brasileiros desde o final do século XIX até meados do século XX, dentre os quais podemos citar Francisco Campos (1936), Amilcar de Castro (1956) e Wilson de Souza Campos Batalha (1961). Nesse sentido, Campos é incisivo ao afirmar que

Mancini não submeteu [...] o princípio [da nacionalidade] a uma elaboração cientifica, suficiente para fundá-lo em bases sólidas. 
Limitou-se a justificá-lo por considerações de ordem geral, como o clima, os costumes, a situação geográfica, etc. [...] todos os fatores, enfim, que influem sobre a formação e o crescimento da personalidade humana. (CAMPOS, 1936, p. 315)

Comungando das mesmas reflexões, Batalha critica Mancini e seus seguidores por terem formulado uma doutrina popular de cunho político e não uma doutrina cientifica (BATALHA. 1961, p. 198). No entanto, a crítica mais contundente vem de Castro. Segundo o autor, o que menos pretendia Mancini era criar uma construção jurídica, já que seu trabalho não passava de pura manifestação oratória, onde não se encontrava uma teoria concatenada em sucessão lógica de proposições abstratas. Conclui dizendo que Mancini apenas apresentou uma inspiração ou uma sugestão, sem, contudo, estabelecer um sistema (CASTRO, 1956, p. 196).

Nos primeiros anos do século XX, os responsáveis pelos projetos do Código Civil, em particular, Clóvis Beviláqua, cuidam da matéria de direito internacional privado e a disciplinam na Lei de Introdução ao Código Civil de 1916, elegendo o elemento de conexão da nacionalidade como aquele ideal tendo em vista o estatuto pessoal da pessoa física $\left(\operatorname{art.~} 8^{\circ}\right)^{7}$. A lei do domicílio só se aplicava de modo subsidiário (art. $9^{\circ}$ ), quando a pessoa fosse apátrida ou possuísse mais de uma nacionalidade. Philadelpho Azevedo levanta a hipótese de que a aplicação do critério da nacionalidade no Brasil foi devida ao "francesismo", isto é, à tendência do direito internacional privado em imitar a legislação francesa (AZEVEDO, 1942, p. 352), não fazendo referência à doutrina do jurista italiano.

A referência ao ordenamento jurídico francês ocorre em razão do disposto no artigo $3^{\circ}$, alínea 3 do Código Civil Napoleônico de 1804, o qual prevê que "Les lois concernat l'état et la capacité des personnes régissent les Français, meme resident en pays étranger". Note-se, como já mencionado, que é adotada a lei da nacionalidade como critério de conexão para determinar a capacidade do francês que morasse no exterior e não de modo geral, de forma a impedir a aplicação da lei nacional ao es-

\footnotetext{
${ }^{7}$ Art. $8^{\circ}$ da LICC de 1916 dispunha: "A lei nacional da pessoa determina a capacidade civil, os direitos de família, as relações pessoais dos cônjuges e o regime dos bens no casamento, sendo lícito quanto a este a opção pela lei brasileira".
} 
trangeiro residente em território francês, diferindo, em parte, do princípio aplicado no Brasil.

Ao analisar o conteúdo desse artigo, Erik Jayme afirma que "[...] il ne règle et la capacité des étrangers; il est, comme dira Mancini plus tard, 'une formule incomplète'.” (JAYME, 1982, p. 24). O autor alemão vai além e assevera que o Código civil napoleônico não contém regras especiais, pois o estado e a capacidade das pessoas são termos jurídicos muito amplos que encontrarão diferentes interpretações nos diversos sistemas que sobrevieram ao Código civil (1982, p. 24). Por exemplo, na França o estatuto pessoal não compreende o regime matrimonial e a sucessão, ou seja, somente os direitos extrapatrimoniais relativos ao direito de família são abrangidos por essa categoria (MAEYZEAUD-GARAUD, 2008, p. 59).

Atento aos pontos fracos da teoria de Mancini, Clóvis Beviláqua, muito embora tenha sido favorável à adoção da lei da nacionalidade, tece severas críticas à doutrina pura de Mancini, sobre a qual afirma que se tem levantado graves objeções. Critica a ideia de que seria uma violação da soberania nacional do Estado não permitir que este tenha a competência de dar leis aos seus nacionais expatriados. Esse raciocínio, que se funda na junção do direito internacional privado ao público, parece ser, na visão de Beviláqua, uma ideia errônea, haja vista que se apresenta como uma faca de dois gumes:

Se é ofensivo da soberania dos Estados impor aos seus súditos leis estrangeiras, quando eles se acham no estrangeiro, pode também ser desrespeitoso a essa mesma soberania tolerar dentro de um Estado que imperem outras leis além das que ele entendeu necessárias à direção da vida social, a que preside. Depois, se o argumento procedesse, como justificar as exceções oriundas da ordem pública e da forma dos atos? (BEVILÁQUA, 1944, p. 57)

Não tardou para que vozes começassem a reclamar a substituição da lei nacional pela do domicílio. Ainda em 1916, Rodrigo Otávio (1916, p. 428) publica artigo em que critica a teoria de direito internacional privado desenvolvida por Mancini, alegando que não é mais do que uma “expressão filosófica" das ideias das antigas escolas estatutárias. Corro- 
borando tal reflexão, Amilcar de Castro, na década de 1950, também se posiciona no sentido de que "Mancini seria um neo-estatutário, bastando para tanto observar a denominação da doutrina personalidade do direito" (CASTRO, 1956, p. 199).

Sob o frenesi da entrada em vigor do primeiro Código Civil brasileiro, foi realizado no Rio de Janeiro, no ano de 1922, o Congresso Jurídico, no qual Rodrigo Otávio defendeu a adoção do princípio do domicílio, vindo a ser acatada pelo Congresso. Nesse período, o Brasil permanecia isolado no continente latino-americano, rompendo com a antiga tradição somente em 1942, com a reforma da Lei de Introdução ao Código Civil que substituiu o elemento de conexão da nacionalidade por aquele do domicílio, cuja redação se mantem inalterada ainda hoje ${ }^{8}$.

$\mathrm{Na}$ Exposição de Motivos da citada reforma, fica claro o discurso a favor da lei do domicílio como sendo o critério mais apropriado para disciplinar tais relações, sendo considerado um vínculo jurídico mais seguro em um país de imigração como o Brasil. Dada a vasta extensão territorial e a necessidade de integrar melhor os estrangeiros aqui residentes, a adoção da regra do domicílio apresentava-se como uma necessidade de ordem pública, imposta por um sentimento de legítima defesa da vida nacional.

Interessante notar que tal justificativa legislativa encontra respaldo nos ensinamentos doutrinários de Carlos Augusto de Carvalho que já em 1899 assinalava que o princípio da nacionalidade não se mostrava condizente com as nações americanas, pois estas recebiam milhares de imigrantes de todas as nacionalidades e que, dessa forma, acabariam por perder rapidamente sua própria coesão e os imigrantes continuariam a ser regidos segundo as leis da sua pátria abandonada. Continuava o autor afirmando que a unidade política destes países, expressão elevada da soberania, não tardaria a se ressentir da unidade legislativa e o fraciona-

${ }^{8}$ Art. $7^{\circ}$ e $10^{\circ}$ da LICC de 1942 , com redação mantida pela reforma de 2010: Art. $7^{\circ}$ "A lei do país em que domiciliada a pessoa determina as regras sobre o começo e o fim da personalidade, o nome, a capacidade e os direitos de família;" Art. 10: "A sucessão por morte ou por ausência obedece à lei do país em que domiciliado o defunto ou o desaparecido, qualquer que seja a natureza e a situação dos bens". 
mento seria uma ameaça constante a sua integridade (CARVALHO, 1899, p. LXXXII).

Seguindo a mesma linha de raciocínio, porém após a adoção do critério de conexão do domicílio, se manifestou Wilson de Souza Campos Batalha (1961, p. 199). Inspirado nas lições do francês Jean-Paulin Niboyet, pondera Batalha que Mancini peca em suas pretensões universalistas, pois assim como há países de emigração, há também países de imigração e nestes os interesses são contrários aos dos primeiros, não se lhes adaptando o princípio da lei nacional.

Curioso observar que tanto a justificativa apresentada na Exposição de Motivos da reforma da Lei de Introdução quanto as teorias formuladas pelos doutrinadores brasileiros em nada se identificam com as razões que Savigny expusera para justificar a teoria do domicílio como competente para reger a pessoa (DOLINGER, 2011, p. 321). Este procura estabelecer o critério de conexão fundado na natureza das relações jurídicas, indicando como princípio fundamental o da sede da relação jurídica. O jurista alemão concede relevante papel à intenção das pessoas, situando-a como centro de toda relação jurídica (DAL RI, 2004, p. 12). Assim, cada indivíduo escolhe o local de seu domicílio e é pela lei deste local que se deve reger a condição da pessoa, isto é, seu estatuto pessoal (SAVIGNY, 2004, p. 128-150), pois é aí que se encontra o direito mais conforme a natureza do fato, isto é, seu centro de gravidade. A regra da teoria de Savigny é que o estado e a capacidade das pessoas sejam regulados pela lei domiciliar, mas se o indivíduo possui mais de um domicílio, prefere-se o mais antigo; se não tem domicílio, conforme o caso, aplica-se a lei do último domicílio ou a do domicílio do pai na época do nascimento ou da residência da pessoa, ou ainda do lugar em que se encontrar.

Entre as décadas de 1950 e 1970, a doutrina brasileira, já adaptada à nova regra de conexão do domicílio, ao referenciar a doutrina de Mancini, alerta para o caráter extremista do seu discurso ao mesmo tempo que constata serem as exceções ao princípio da nacionalidade mais recorrentes do que a regra. A importância dada ao vínculo da nacionalidade, segundo Oscar Tenório (1965, p. 397), é excessiva, havendo uma tendência de genera- 
lizar incompatível com a realidade. Por sua vez, Sérgio Loreto Filho afirma que houve um "surto da doutrina" nos Estados europeus e que

O advento da pregação doutrinária de Mancini fez surgir uma nova orientação doutrinária, que poderíamos acoimar de extremista - a Escola Italiana Moderna - a qual, endossando o princípio da lei nacional como representando o verdadeiro estatuto pessoal, exagerou a sua aplicação ao ponto de encarar essa mesma aplicação como uma regra geral para a solução de todos os conflitos de leis. (LORETO FILHO, 1973, p. 61)

Sob o ponto de vista técnico, Wilson de Souza Batalha (1961, p. 199) pondera que "[...] o número das exceções ultrapassa a regra, destruindo-a". De modo elucidativo, Amilcar de Castro (1956, p. 198) pondera que apesar de a teoria de Mancini fundar-se na regra geral da extraterritorialidade do direito, as exceções são tantas que vão ao ponto de inutilizá-la. Complementa sua crítica ao afirmar que os casos em que deve ser observado direito diferente do nacional, como para evitar ofensa à ordem social, ou por força das circunstâncias, do lugar do ato, ou da situação da coisa, ou da autonomia da vontade, são tão numerosos, que acabam por abafar a pressuposta regra geral.

\section{Conclusão}

Diante do exposto, a presente pesquisa buscou sinteticamente apresentar o modo como foi recepcionada a teoria do princípio da nacionalidade de Mancini sob a perspectiva da doutrina de direito internacional privado brasileira e sua interação com as opções legislativas adotadas nos séculos XIX e XX quanto ao critério de conexão para determinação da lei aplicável ao estatuto pessoal do indivíduo nos casos em que a relação jurídica apresente algum elemento de estraneidade.

É possível afirmar a existência de correntes doutrinárias críticas ao princípio da lei nacional mesmo no período em que a legislação pátria o adotava como regra geral para resolução dos conflitos de leis. Observa-se que após a reforma legislativa de 1942, que introduziu a regra de conexão 
da lex domicilii, a doutrina brasileira endurece ainda mais seus questionamentos acerca do caráter não universal do princípio da nacionalidade e da ausência de tecnicidade da teoria proposta por Mancini.

Além disso, foi possível analisar que diversos autores brasileiros atribuem ao direito francês a verdadeira origem da influência do critério de conexão da nacionalidade na doutrina e na legislação pátria, nada mencionando ou, até mesmo, rechaçando expressamente o princípio teorizado pelo jurista italiano. De fato, Pimenta Bueno na primeira obra compilada de direito internacional privado no país ao tratar deste tema faz apenas referência ao francês Foelix e ao respectivo código civil, embora tenha sido constatado que o modo com o critério da nacionalidade é adotado pela legislação francesa divirja parcialmente da forma de aplicação do mesmo pelo ordenamento jurídico brasileiro.

Por fim, interessante notar que a unanimidade dos doutrinadores analisados citam Savigny como o mentor do princípio do domicílio, mas ao justificarem a conveniência e, inclusive, a necessidade de utilização do mesmo pelo ordenamento jurídico brasileiro, fazem alusão à argumentos diametralmente diferentes daqueles que nortearam o fundamento da teoria do jurista alemão no século XIX, de certo modo "adaptando-a" aos interesses e ao contexto nacional o que, em realidade, representa uma verdadeira desconfiguração do conteúdo do instituto formulado por Savigny.

\section{Referências}

ANZILOTTI, Dionisio. Scritti di diritto Internazionale privato. Padova: CEDAM, 1960. v. III.

AZEVEDO, Filadelfo de. [título não encontrado]. Revista Forense, [S.l.], v. 92, 1942.

BASSO, Maristela. Curso de Direito Internacional Privado. 3. ed. São Paulo: Atlas, 2013.

BATALHA, Wilson de Souza Campos. Tratado elementar de direito internacional privado. São Paulo: Revista dos Tribunais, 1961. v. I. 
BEVILAQUA, Clóvis. Princípios elementares de Direito Internacional Privado. 4. ed. Rio de Janeiro: L. Freitas Bastos, 1944. BONI, Andrea de; FERRERO, Marco. Dalla cittadinanza etno-nazionale alla cittadinanza di residenza. Diritto, Immigrazione e Cittadinanza. Milano: Franco Angeli, 2004. Anno V, n. 4.

BUENO, Pimenta. Direito Internacional Privado e aplicação de seus princípios com referencia às leis particulares do Brazil. Rio de Janeiro: Typographia Imp. E Const. de J. Villeneuve E. C. 1863.

CAMPOS, Francisco. Exposição de motivos. Pareceres, [S.l.], 2 ${ }^{\mathrm{a}}$ série, 1936.

CARVALHO, Carlos Augusto de. Direito civil brasileiro recopilado ou nova consolidação das leis civis. Rio de Janeiro: L. Francisco Alves, 1899.

CASTRO, Almicar de. Direito Internacional Privado. Rio de Janeiro: Forense, 1956.

CATELLANI, Enrico Levi. Il Diritto internazionale privato e i suoi recenti progressi: Il Savigny, la Scuola italiana e gli sviluppi più recenti della dottrina dell'ordine pubblico. 2 ed. Torino: Unione Tipografico Editrice, 1902.

COSTA, Pietro. Cittadinanza. Roma-Bari: Editori Laterza, 2013.

DAL RI Jr., Arno. Apresentação. In: SAVIGNY, Friedrich Carl von. Sistema do direito romano atual. Ijuí: Editora Unijuí, 2004. v. VIII. DOLINGER, Jacob. Direito Internacional Privado. 10. ed. Rio de Janeiro: Forense, 2011.

FREITAS, Augusto Teixeira de. Consolidação das leis civis. 3. ed. Rio de Janeiro: L. Edictor do Instituto Histórico, 1876.

GROSSI, Paolo. Mitologias jurídicas da modernidade. 2. ed. Florianópolis: Boiteux, 2007. p. 13-20.

. O ponto e a linha: história do direito e direito positivo na formação do jurista do nosso tempo. Revista Sequência: Estudos Jurídicos e Políticos, Florianópolis, n. 5, p. 31-45, dez. 2005. 
JAYME. Erik. Introduzione. In: JAYME. Erik (a cura di). Della nazionalità come fondamento del diritto delle genti. Torino: G. Giappichelli, 2000.

. Considérations historiques et actuelles sur la codification du droit international privé. Recueil des cours: collected courses of the Hague Academy of International Law. The Hague/Boston/London: Martinus Nijhoff Publishers. 1982. v. IV, T. 177.

LESSA, Pedro. O direito no século XX. Revista da Faculdade de Direito de São Paulo, São Paulo, v. VIII, 1900.

LORETO FILHO, Sérgio. Curso de Direito Internacional Privado. Recife: Ed. Universitária, 1973.

MANCINI, Pasquale Stanislao. Prelezione al corso di diritto pubblico esterno ed internazionale privato, tenuta da P.S. Mancini nella R. Università do Torino, il 22 gennaio 1851. In: JAYME. Erik (a cura di). Della nazionalità come fondamento del diritto delle genti. 2000.

. Utilità di rendere obbligatorie per tutti gli Stati, sotto la forma di uno o più trattati, alcune regole del diritto internazionale privato per assicurare la decisione uniforme dei conflitti tra le differenti legislazioni civili e criminali. Diritto Internazionale, [S.l.], n. 12, 1959.

MEYZEAUD-GARAUD, Marie-Christine. Droit International Privé. 2. ed. Rosny-sous-Boix: Bréal, 2008.

MIRANDA, Pontes de. La conception du Droit International Privé d'après la Doctrine et la Pratique au Brésil. Récueil des Cours de l'Académie de Droit International. tomo XXXIX, 1932.

. Tratado de Direito Internacional Privado. Tomo II. Rio de Janeiro: L. José Olympio, 1935.

MOSCONI, Franco; CAMPIGLIO, Cristina. Diritto Internazionale Privato e Processuale: parte generale e obbligazione. 5. ed. Milano: UTET, 2010. v. I.

OCTÁVIO, Rodrigo. A Theoria de Mancini. Revista Jurídica, [S.l.], v. II. 1916. 
PIHLAJAMAKI, Heikki. Comparative Contexts in Legal History: are we all comparatists now? Revista Sequência: Estudos Jurídicos e Políticos, Florianópolis, n. 70, p. 57-75, jun. 2015.

PILLET, Antoine Mélanges. Principes de Droit International Privé. Paris: Pedone Éditeur, 1903.

SANTLEBEN, Jurgen. Teixeira de Freitas e a autonomia das partes no direito internacional privado latino-americano. Revista de Informação Legislativa, [S.l.], Ano 22, n. 85, jan.-mar. 1985.

SAVIGNY, Friedrich Carl von. Sistema do direito romano atual. Ijuí: Unijuí, 2004.

STORTI STORCHI, Claudia. Mancini, Stanislao Pasquale. Dizionario dei giuristi italiani. Bologna: il Mulino, 2013. v. II.

Ricerche sulla condizione giuridica dello straniero in Italia dal tardo comune all'età Preunitaria Aspetti civilistici. Milano: Giuffré, 1990.

TENÓRIO, Oscar. Direito Internacional Privado. 8. ed. Rio de Janeiro: F. Bastos, 1965. v. I.

VALLADÃO, Haroldo. Direito Internacional Privado: em base histórica e comparativa, positiva e doutrinaria, especialmente dos Estados americanos. Rio de Janeiro: F. Bastos, 1973.

Direito Internacional Privado. Rio de Janeiro: Freitas Bastos, 1967. v. I.

VITTA, Edoardo. Il principio di nazionalità nel diritto internazionale privato italiano. Rivista di Diritto Internazionale Privato e Processuale, [S.l.], Anno XVI. Padova: CEDAM, 1980.

WALD, Arnoldo. A obra de Teixeira de Freitas e o Direito LatinoAmericano. Revista de Informação Legislativa, [S.l.], n. 163, 2004. 
Aline Beltrame de Moura é Professora Adjunta no Curso de Graduação em Direito da Universidade Federal de Santa Catarina (UFSC). Professora Permanente do Curso de Pós-Graduação em Direito da UFSC. Doutora em Direito pela Università degli Studi di Milano, Itália. Foi Visiting Researcher no Max Planck Institute for Comparative and International Private Law em Hamburgo, Alemanha. Cocoordenadora do Grupo de Pesquisas em Direito Internacional Ius Gentium CNPQ/UFSC. Coordenadora do Grupo de Estudos em Arbitragem Internacional (GEARB UFSC). Vencedora do Prêmio Riccardo Monaco de melhor tese de doutorado na área de direito internacional defendida na Itália em 2014.

E-mail: alineb.moura@gmail.com .

Endereço profissional: Universidade Federal de Santa Catarina - Campus Universitário. Trindade - Florianópolis - SC - Brasil. CEP: 88040-900. 